\title{
Youth Virtue Self-Esteem and Positive Presentation in Social Media Instagram
}

\author{
Tiara Anggita Perdini ${ }^{1}$, Erik Saut H Hutahaean ${ }^{2}$ \\ \{erik.saut@dsn.ubharajaya.ac.id $\left.{ }^{2}\right\}$ \\ Psychology, Bhayangkara Jakarta Raya University, Indonesia ${ }^{1,2}$
}

\begin{abstract}
This research departs from the phenomenon of self-existence or also called selfexpression among users of social media Instagram. This phenomenon can cause problems, one example is data leakage, which can occur if one shows oneself too often on Instagram social media. The data leaked is usually misused by other parties for their interests. The purpose of this study is to analyze the variables of self-esteem and self-presentation related to this phenomenon, especially to find out the forms of self-esteem and self-presentation that users do on Instagram. The research subjects included 110 teenage Instagram users involved based on their willingness to fill out the self-esteem and self-presentations questionnaires. This study uses variance analysis techniques towards the data, particularly to compare the average total score on variable aspects. The results of the analysis show that the four aspects of self-esteem have different average values and that virtue is the most sought-after form of self-esteem. Likewise, the comparison of the five aspects of selfpresentation shows that the positive one is the dominant form performed by the subjects. This research is expected to provide theoretical benefits in the field of social psychology, and in practical terms, to provide an overview of self-presentation on Instagram.
\end{abstract}

Keywords: Self-presentation, positive; self-esteem, virtue, instagram

\section{Introduction}

Many people use the internet these days, even the internet has become a necessity for individuals today [1]. From children to parents, they all become internet users [2]. On average people use the internet to view social media [3]. Media social Instagram is one of the most widely used social media. According to survey data, Instagram is the third most used social media after YouTube and Facebook [4]. Instagram is much popular for its focus on images so that it can enhance one's self-image. This uniqueness also attracts teenagers to use it, while at their age they can learn anything, especially technology, more quickly [5]. Through Instagram, one can express oneself and show off, and get feedback from other users as proof of one's existence [6]. Often in expressing themselves on Instagram, people will post their daily activities, and decorate the post to make it look attractive, such as adding filters, adding place descriptions, and so on. However, posting too much on Instagram will cause problems, one example is data leakage [7]. Instagram as a social media is also vulnerable to data leakage [8]. The data leaked will then be used and utilized by other parties for their personal gain [9]. In using Instagram, an individual displays several characteristics such as always showing himself/herself wherever and whenever to get praise and attention from others, this can be called self-presentation. 
Self-presentation is a behavioural action related to individual awareness to build the desired impression on other individuals [10]. Instagram users show their self-presentation by sharing photos, videos, interesting articles or sentences, and also show their personal identity [11]. Making self-presentation through Instagram indicates a relationship established by CMC (computer-mediated communication), not by FTF (Face to Face) [12]. According to Huang in 2014 [13], there are four ways that social media users use to improve their presentation. Firstly, ingratiation, that is when Instagram users pay attention and give praise to other users to show kindness and concern. Secondly, users control the impact of damage by increasing their positive impression and reduce their negative impression. This is also related to how individuals apologize to other users when they make mistakes. The third one is manipulation, that is when individuals comment negatively on other users and develop a strategy of denial when being blamed for something and provide a logical explanation of why these other users deserve negative comments. The last one is self-promotion. In this case, individuals will usually use social media to share something positive about themselves, such as their achievements and positive activities.

According to Yang and Bradford Brown in 2016 [14], online self-presentation has five dimensions, namely breadth of information, depth of information, positivity, authenticity, and intentionality. Firstly, the breadth of information refers to the quantity or amount of information that is shared and presented to other users or individuals in general. Secondly, the depth of information refers to the extent to which personal information is shared and presented to individuals in general. Thirdly, positivity refers to how far and how much information can provide a good image to optimize the self-image as an individual want. Fourthly, authenticity means here refers to how accurate the information provided can describe the individual. And finally, intentionality means the extent to which individuals are aware of and know the information shared. The self-presentation that everyone demonstrates is different, related to the factors that affect it. According to Salim, et al. One of the important factors in building selfpresentation is self-esteem [15].

Coopersmith explains that self-esteem is an assessment that one does in relation to oneself, which can reflect an acceptance or rejection, and shows how much the one feels oneself valuable [16]. The self-esteem aspects which Coopersmith put forward [17] are as follows. Firstly, the aspect of power, concerning how strongly individuals can rule and control themselves and others. The second aspect is meaningfulness, concerning the care, attention, and affection that an individual receives from others and serves as a sign of acceptance and popularity. The third one is the virtue, in this case, described as compliance with morals, ethics and principles in religion marked by doing allowed behaviour and avoiding prohibitions. The fourth aspect is the ability, that is when individuals show their success through achievements or completed tasks as requested.

Previous studies have discussed a lot about self-presentation and self-esteem. Like Kramer and Winter's research in 2008, this research found that self-efficacy affects self-presentation, so it can also affect the number of virtual friends, profile details and types of poses. It was also explained that self-esteem did not significantly affect self-presentation [18]. In line with the research of Salim et al., in 2017 which found that self-presentation is affected by the fear of being left behind, while the fear of being left behind is affected by the self-esteem. Self-esteem cannot directly affect self-presentation and must be mediated by a fear of being left behind [15]. This result is inversely proportional to Mehdizadeh's study in 2010, which found that selfpresentation and self-esteem are interrelated in opposite directions. Low self-esteem will increase self-presentation and vice versa [19]. Through this study, the researcher wanted to examine and make a deeper exploration of self-presentation and self-esteem. This study will 
analyze the dimensions or aspects of the self-presentation and self-esteem variables in Instagram users. This study is aimed at finding out the ways Instagram users use in presenting themselves and kinds of self-esteem they wish to have. This research is expected to provide new knowledge and understanding of self-presentation and self-esteem to young Instagram users.

\section{Method}

This study is quantitative research, supported by its research questions and data. This study will show how the research will relate to data obtained from the field, and explain the procedures and tools used [20]. The data collected in this study involved 110 respondent subjects who were teenagers and actively used social media Instagram. The subjects were selected based on their willingness to fill out self-presentation and self-esteem questionnaires based on the theories of aspect and dimension. Self-esteem variables were arranged based on the Coopersmith's theory of aspect [17], while self-presentation variables were arranged based on the dimensional theory that Yang \& Bradford Brown put forward [14]. By employing the theories of aspect and dimension, several indicators are then obtained. From this indicator, the items or statements are formed for the respondents to choose and fill.

Towards the obtained data, the assumption test will be carried out first. Several assumption tests include normality, linearity, and homogeneity tests. Normality test is needed to see whether the research data is normally distributed or not, so the next analysis technique can be decided (non-parametric or parametric) [21]. The linearity test is to see whether the research data were evenly distributed among the research subjects (respondents) [22]. Homogeneity test is used to see whether the data is homogeneous or heterogeneous. After carrying out the assumption test, the data is processed and analyzed through analysis of variance (Anova). Analysis of variance is mainly used for comparing the total average score on each aspect of the two variables (selfesteem and self-presentation) [23]. This is used to dig deeper, which aspects (of each variable) the subject uses the most. In the analysis of variance, the total average score on each aspect of each variable will be compared, to find out which aspects are used most often. This study uses the analysis of variance Multivariate to measure aspects and dimensions of more than one variable. Multivariate is a method that aims to analyze a lot of data of the variables that assumed related to each other [24].

\section{Result and Discussion}

\subsection{Presenting the results}

This study focuses on finding answers about what self-esteem looks like, and what kind of self-presentation is that Instagram users look for, therefore test assumptions and analysis of dimensions or aspects of each variable are used for the analysis. The results show that most Instagram users demonstrate positive self-presentation to get self-esteem which is considered a virtue. This is based on the results of the total average score and the categorization that has the highest number of subjects. The explanation of the research results in more detailed is given as follows. 


\subsubsection{Assumption test}

The assumption tests used in this research are the normality test, linearity test, and homogeneity test. The assumption test results can be seen in the table below (Table 1). The result of the Assumption Test shows that the self-presentation variable and self-esteem variable are normally distributed with a normality value 0.200 for both variables.

Table 1. Assumption Test

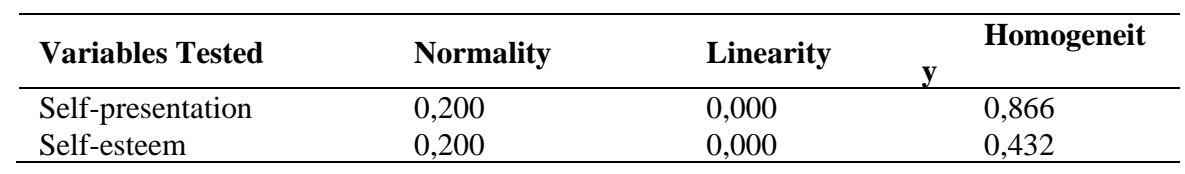

Both variables are also declared linear with a linear significance value of 0.000 . Furthermore, the homogeneity value of the self-presentation variable is 0.866 and the selfesteem variable is 0.432 . The result shows that the two variables are homogeneous since both passes the assumption test. Thus, the next analysis technique that can be used is parametric analysis.

\subsubsection{Analysis of self-presentation and self-esteem dimensions}

The next test is the Analysis of dimensions or aspects of self-presentation and self-esteem variables, while self-presentation has five dimensions and self-esteem has 4 aspects. This study uses parametric analysis techniques, namely the Anova test. The results of data analysis can be seen in the table below. Table 2 shows the results obtained from the analysis of the dimensions of self-presentation. For the breadth of information, the average value is 10.247 , the F value is 3.829 , and the significance is 0.000 , which means that there is a significant difference with other dimensions. Also, the subjects have been grouped into 3 (three) categories, namely low, medium, and high.

Tabel 2. Analysis of self presentation dimensions

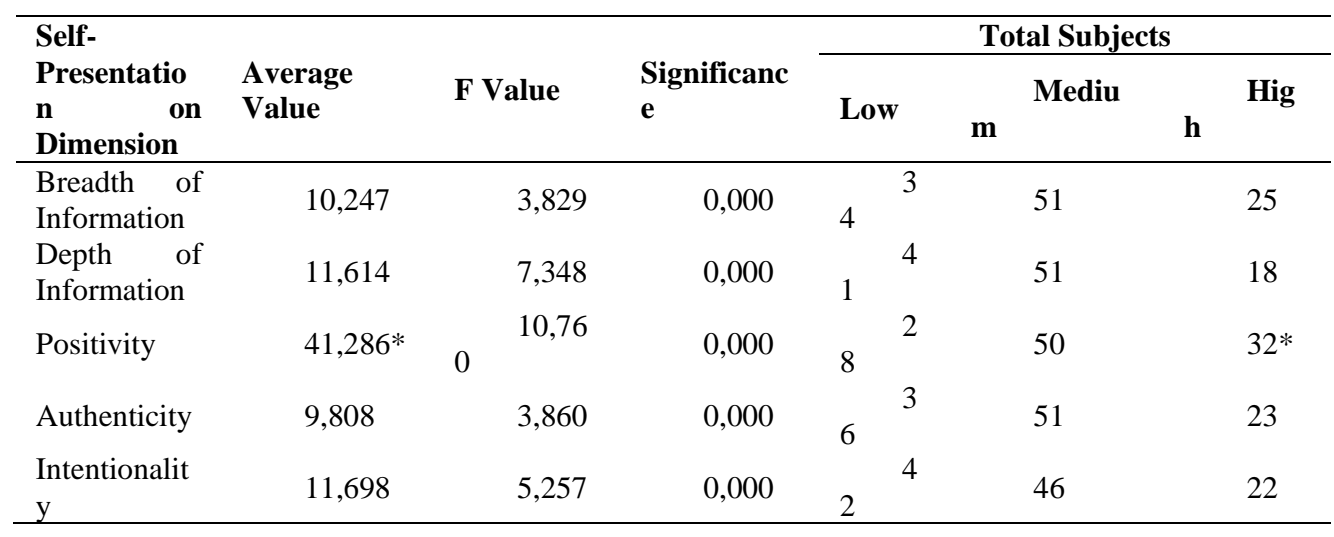

For the breadth of information, there are 34 subjects in the low category, 51 in the medium category, and 25 in the high category. For the next dimension, that is the depth of information, 
the average value is 11.614 , the $\mathrm{F}$ value is 7.348 and the significance value is 0.000 , which indicates a significant difference with other dimensions. For the dimension of depth of information, there are 41 subjects in the low category, 51 in the medium category and 18 in the high category. For the third dimension, namely positivity, the average value is 41.286 , the $\mathrm{F}$ value is 10.760 , and the significance value is 0.000 . There are 28 subjects in the low category, 50 people in the medium category and 32 people in the high category. For the dimension of authenticity, the average value is 9.808 , the $\mathrm{F}$ value is 3.860 , and the significance value is 0.000 . Judging from the total subject, there are 36 subjects in the low category, 51 people in the medium category and 23 people in the high category. Finally, for the dimension of intentionality dimension has a mean value of 11.698, an F value of 5.257 and a significance value of 0.000 . In the intentionality, the total number of subjects includes 42 people in the low category, 46 in the medium category and 22 in the high category. The aspects of the self-esteem variables will be also further discussed. Table 3 shows the aspects regarding self-esteem. The first aspect, namely power. As explained in the table, its average value is 12.288 , its $F$ value is 4.157 and its significance is 0.000 .

Table 3. Analysis of Self-Esteem Aspects

\begin{tabular}{|c|c|c|c|c|c|c|}
\hline \multirow[b]{2}{*}{$\begin{array}{l}\text { Self-Esteem } \\
\text { Aspects }\end{array}$} & \multirow[b]{2}{*}{ Average Value } & \multirow[b]{2}{*}{ F Value } & \multirow[b]{2}{*}{ Significance } & \multicolumn{3}{|c|}{ Total Subjects } \\
\hline & & & & Low & $\begin{array}{l}\text { Mediu } \\
\text { m }\end{array}$ & High \\
\hline Power & 12,288 & 4,157 & 0,000 & 3 & 48 & 59 \\
\hline Significance & 11,145 & 3,261 & 0,000 & 1 & 55 & 44 \\
\hline Virtue & $37,465^{*}$ & 10,80 & 0,000 & 1 & 44 & 65 \\
\hline Ability & 26,206 & 6,621 & 0,000 & 4 & 65 & 41 \\
\hline
\end{tabular}

This means that this aspect has a significant difference from other aspects. Its total subjects (as categorized) include 3 people in the low category, 48 people in the medium category and 59 people in the high category. The second aspect is the significance, which as shown in the table has the average value 11.145 , the $F$ value 3.261 , and the significance value 0.000 . Its total subjects consist of 11 people in the low category, 55 people in the medium category, and 44 people in the high category. The third aspect is the virtue, as described in the table has the average value 37.465 , the $F$ value 10.800 , and the significance value 0.000 . Its total subjects include 1 person in the low category, 44 people in the medium category, and 65 people in the high category. Finally, the fourth aspect, namely the ability, as seen in the table has the average value 26.206 , the $F$ value 6.621 , and the significance value 0.000 . The total subjects of this aspect consist of 4 people in the low category, 65 people in the medium category, and 41 people.

\subsection{Discussion}

This research has managed to generate the latest findings, different from other studies that talks about self-presentation and self-esteem on social media, especially Instagram. Joanna C. Yau and Stephanie M. Reich in 2019 conducted research related to self-presentation and concluded that perspective-taking and approval from peers can affect online self-presentation [25]. Furthermore, similar research was also carried out by Rachel Grievea, Evita Marchb, and Jarrah Watkinson in 2020, which showed that the dimensions of authenticity on social media Facebook were influenced by narcissism. The higher the level of narcissism is, the lower self- 
esteem is. Therefore, individuals need the authenticity of their self-image to support their selfpresentation [26]. Research conducted by Seoyeon Hong, Rosie M. Jahng, and Namyeon Lee, Kevin R in 2020 found another result (still related to authenticity), that individual Instagram users often use interesting filters to improve their presentation [27].

However, this study has different results from previous studies mentioned. Instead of the authenticity dimension, the positivity dimension of the self-presentation variable is the most often appears in the subject. This can be seen in Table 3, where the average value for the positivity dimension is the highest, which is 41.286 . The result is also supported by the result of subjects' categorization of which 32 subjects have high positivity. Next, the result also shows that the virtue aspect of the self-esteem variable is the one that Instagram users often look for. Of the four self-esteem aspects, virtue has the highest average value, which is 37.465 . This result is supported by the results of subjects' categorization, of which 65 subjects have high virtue value. The results of these two variables show that the subjects (Instagram users) tend to perform a positive presentation in search of virtue in themselves.

In using Instagram, the majority of Instagram users perform a positive presentation about themselves. Especially on Instagram, they can engage themselves selectively and also build a positive self-presentation. This is relatively easy to do thanks to today's technology, such as the ability to edit and maintain asynchrony [28]. Individuals who are looking for a positive impression will usually build many friendships, post important day celebrations or important events, and try their best to form their profile as best as possible [18]. They often show positive self-presentation to people they do not know or people outside their inner circle, while to those closest to them, individuals will be more confident in presenting their true self [29]. Through Instagram, users can build good personal relationships, especially with other users who they don't really know [15].

Showing a positive self-presentation can also provide a touch of expression of one's identity [30]. It is related to virtue in one's self-esteem. The more positive the impression the individual has, the better the morals and norms (virtues) they own in the eyes of other users [31]. Kwan, Kuang, and Hui in their study stated that one of the main sources of self-esteem is virtue [32]. Through virtue, Instagram users can get more happiness and see themselves more positively [33]. Individuals who have a positive perception about themselves will ultimately have high self-esteem [32]. This study has limitations since it only examines online self-presentation and self-esteem. This does not provide a broader knowledge. Future research will need to examine self-presentation and self-esteem in person to demonstrate comparative results (in person and online).

\section{Conclusion}

An individual who shows himself/herself on Instagram all the time is considered to have made a self-presentation. Self-presentation on social media, especially Instagram, is related to self-esteem. Self-presentation has five dimensions, namely the breadth of information, depth of information, positivity, authenticity, and intentionality. From these five dimensions, it is found that the positivity dimension is the way individuals often present themselves on Instagram. There are also self-esteem aspects, namely power, significance, virtue, and ability. From the four self-esteem aspects, virtue is the aspect that Instagram users want to show the most. From these findings, it can be seen and concluded that individuals more often post something positive about themselves on Instagram to be considered having behaviour. Future research is expected 
to examine self-presentation and individual self-esteem offline (not online via social media), to compare whether the results obtained remain the same or different from online self-presentation and online self-esteem.

\section{Acknowledgements}

We would like to express our deepest gratitude to the Bhayangkara Jakarta Raya University for facilitating the writing of this article so that we can complete this article on time.

\section{References}

[1] D. J. Mills and J. J. Allen, "Self-determination theory, internet gaming disorder, and the mediating role of self-control," Comput. Human Behav., vol. 105, p. 106209, 2020.

[2] H. Nicholl, C. Tracey, T. Begley, C. King, and A. M. Lynch, "Internet use by parents of children with rare conditions: Findings from a study on parents' web information needs," J. Med. Internet Res., vol. 19, no. 2, pp. 1-18, 2017.

[3] APJII, "Potret Zaman Now Pengguna \& Perilaku Internet Indonesia," Bul. APJII, p. 1, 2018.

[4] "Digital in 2019," We Are Social, 2019.

[5] A. M. Manago, S. Guan, and P. Greenfield, "New Media, Social Change, and Human Development from Adolescence Through the Transition to Adulthood," Dev. Psychol., pp. 1-27, 2015.

[6] T. Takahashi, "Creating the Self in the Digital Age: Young People and Mobile Social Media," pp. 44-50, 2011.

[7] V. Paramarta, M. Jihad, A. Dharma, I. C. Hapsari, P. I. Sandhyaduhita, and A. N. Hidayanto, "Impact o f User Awareness, Trust, and Privacy Concerns on Sharing Personal Information on Social Media : Facebook, Twitter, and Instagram," ICACSIS, pp. 271-276, 2018.

[8] R. P. Khandpur, T. Ji, S. Jan, G. Wang, C. T. Lu, and N. Ramakrishnan, "Crowdsourcing cybersecurity: Cyber attack detection using social media," Int. Conf. Inf. Knowl. Manag. Proc., vol. Part F131841, pp. 1049-1057, 2017.

[9] V. Kumar and P. Nanda, "Social Media to Social Media Analytics : Ethical Challenges," Int. J. Technoethics, no. July, 2019.

[10] J. Fox and M. A. Vendemia, "Selective Self-Presentation and Social Comparison Through Photographs on Social Networking Sites," Cyberpsychology, Behav. Soc. Netw., vol. 19, no. 10, pp. 593-600, 2016.

[11] E. Harris and A. C. Bardey, "Do instagram profiles accurately portray personality? An investigation into idealized online self-presentation," Front. Psychol., vol. 10, no. APR, 2019.

[12] M. Tanis and T. Postmes, "Social cues and impression formation in CMC," J. Commun., vol. 53, no. 4, pp. 676-693, 2003.

[13] H. Huang, "Self-presentation Tactics in Social Media," no. Icss, pp. 416-421, 2014.

[14] C. chen Yang and B. Bradford Brown, "Online Self-Presentation on Facebook and Self Development During the College Transition," J. Youth Adolesc., vol. 45, no. 2, pp. 402-416, 2016.

[15] F. Salim, W. Rahardjo, T. Tanaya, and R. Qurani, "Are Self-Presentation Influenced by FriendshipContingent Self-Esteem and Fear Of Missing Out?," Makara Hum. Behav. Stud. Asia, vol. 21, no. 2, p. 70, 2017.

[16] F. G. Goble, Mazhab Ketiga (Psikologi Humanistik Abraham Maslow), 11th ed. Yogyakarta: Kanisius, 2000.

[17] K. Hidayat and K. Bashori, Psikologi Sosial. Jakarta: Erlangga, 2016.

[18] N. C. Kramer and S. Winter, "Impression Management 2.0: The Relationship of Self-Esteem, Extraversion, Self-Efficacy, and Self-Presentation Within Social Networking Sites," J. Media Psychol., vol. 20, no. 3, pp. 106-116, 2008. 
[19] S. Mehdizadeh, "self-presentation 2.0: Narcissism and Self-Esteem on Facebook," Cyberpsychol. Behav. Soc. Netw., vol. 13, no. 4, 2010.

[20] K. F. Punch, Introduction to Social Research Quantitative and Qualitative Approaches, Third. London: SAGE Publications, Inc, 2014.

[21] Y. H. Chan, "Biostatistics 102: Quantitative Data - Parametric \& Non-parametric Tests," Singapore Med. J., vol. 44, no. 8, pp. 391-396, 2003.

[22] L. Bruggemann, W. Quapp, and R. Wennrich, "Test for non-linearity concerning linear calibrated chemical measurements," Accredit. Qual. Assur., vol. 11, no. 12, pp. 625-631, 2006.

[23] A. Gelman, "Discussion paper analysis of variance - Why it is more important than ever," Ann. Stat., vol. 33, no. 1, pp. 1-53, 2005 .

[24] D. Jackson, I. R. White, and R. D. Relay, Handbook of Meta-Analysis: Multivariate Meta-Analysis. 2020.

[25] J. C. Yau and S. M. Reich, “'It's Just a Lot of Work': Adolescents' Self-Presentation Norms and Practices on Facebook and Instagram," J. Res. Adolesc., vol. 29, no. 1, pp. 196-209, 2019.

[26] R. Grieve, E. March, and J. Watkinson, "Inauthentic self-presentation on facebook as a function of vulnerable narcissism and lower self-esteem," Comput. Human Behav., vol. 102, no. August 2019, pp. 144-150, 2020.

[27] S. Hong, M. R. Jahng, N. Lee, and K. R. Wise, "Do you filter who you are?: Excessive selfpresentation, social cues, and user evaluations of Instagram selfies," Comput. Human Behav., vol. $104,2020$.

[28] J. B. Walther, "Selective self-presentation in computer-mediated communication: Hyperpersonal dimensions of technology, language, and cognition," Comput. Human Behav., vol. 23, no. 5, pp. 2538-2557, 2007.

[29] W. (Eric) Jang, E. P. Bucy, and J. Cho, "Self-esteem moderates the influence of self-presentation style on Facebook users' sense of subjective well-being," Comput. Human Behav., vol. 85, pp. 190 199, 2018.

[30] L. J. Human, J. C. Biesanz, K. L. Parisotto, and E. W. Dunn, "Your best self helps reveal your true self: Positive self-presentation leads to more accurate personality impressions," Soc. Psychol. Personal. Sci., vol. 3, no. 1, pp. 23-30, 2012.

[31] K. Kristjansson, Virtues and Vices in Positive Psychology: A Philosophical Critique. New York: Cambridge University Press, 2013.

[32] V. S. Y. Kwan, L. L. Kuang, and N. H. H. Hui, "Identifying the sources of self-esteem: The mixed medley of benevolence, merit, and bias," Self Identity, vol. 8, no. 2-3, pp. 176-195, 2009.

[33] M. W. Martin, "Happiness and virtue in positive psychology," J. Theory Soc. Behav., vol. 37, no. 1, pp. 89-103, 2007. 